\title{
TRIANGULATION AND THE PRIVATE LANGUAGE ARGUMENT
}

\begin{abstract}
The paper attempts a novel defense of the main claim of Wittgenstein's Private Language Argument, i.e. that 'inner' ostensive definition is impossible. Part 1 traces Wittgenstein's target to the idea that 'ostensive definition' is a mental act, an idea that makes it tempting to think that its objects might just as well be private as public. Part 2 discusses a recent interpretation and defence of Wittgenstein's position due to Stroud and McGinn. On their view, private ostensive definition establishes no pattern of use because it fails to specify the type of inner episode that is being ostended. But not explicitly specifying a type is harmless so long as the ostension in fact brings it about that the subject's usage is sensitive to it. Part 3 proposes a new argument. Private ostensive definition does sustain a pattern of use, but that use is semantically indeterminate: nothing in it (or in the subject's mind) settles which of two alternative schemes of reference applies. The conclusion discusses Wittgenstein's best-known remarks on the subject from the perspective of this new argument.
\end{abstract}

Wittgenstein's discussion of private language and related questions in the philosophy of mind occupies 70-odd sections of Philosophical Investigations from around 243 to around 315. But this discussion of it focuses upon just two of them: PI 258 and PI 265:

Let's imagine the following case. I want to keep a diary about the recurrence of a certain sensation. To this end I associate it with the sign "S" and write this sign in a calendar for every day on which I have the sensation. - I first want to observe that a definition of the sign cannot be formulated. - But all the same I can give one to myself as a kind of ostensive definition! - How? Can I point to the sensation? - Not in the ordinary sense. But I speak, or write the sign down, and at the same time I concentrate my attention on the sensation and so, as it were, point to it inwardly. - But what is this ceremony for? For that is all it seems to be! A definition serves to lay down the meaning of a sign, doesn't it? - Well, that is done precisely by concentrating my attention; for in this way I commit to memory the connection between the sign and the sensation. - But "I commit it to memory" can only mean: this process brings it about that I remember the connection correctly in the future. But in the present case, I have 
no criterion of correctness. One would like to say: whatever is going to seem correct to me is correct. And that only means that here we can't talk about 'correct'. (PI 258). ${ }^{1}$

Let us imagine a table, something like a dictionary, that exists only in our imagination. A dictionary can be used to justify the translation of a word X by a word $\mathrm{Y}$. But are we also to call it a justification if such a table is to be looked up only in the imagination? - "Well, yes; then it is a subjective justification." - But justification consists in appealing to an independent authority - "But surely I can appeal from one memory to another. For example, I don't know if I have remembered the time of departure of a train correctly, and to check it I call to mind how a page of the timetable looked. Isn't this the same sort of case?" No; for this process must now actually call forth the correct memory. If the mental image of the timetable could not itself be tested for correctness, how could it confirm the correctness of the first memory? (As if someone were to buy several copies of the morning paper to assure himself that what it said was true.)

Looking up a table in the imagination is no more looking up a table than the image of the result of an imagined experiment is the result of an experiment. (PI 265).

These remarks meet and exceed Wittgenstein's own high standards of unclarity. I'll argue briefly that the line of thought that these remarks can seem to convey is quite unpersuasive; then at greater length that there are other grounds for Wittgenstein's thesis; and in conclusion that this reading casts a more flattering light on the passages that I mentioned. But first I'll describe Wittgenstein's target in a little more detail.

\section{Private ostensive definition}

This section (1.1) introduces Wittgenstein's target by outlining the line of thought that leads to it; and then (1.2) circumscribes the kind of argument against it that I'll be considering here.

\subsection{A mental act of naming}

There is such a thing as ostensively 'naming' something. It happens e.g. in the formal or informal ceremonies that we call the 'baptism' or 'christening' of an object. Let us start with a paradigmatic example of such a ceremony: the christening of a child in a (Christian) church ceremony. Many aspects of this central case seem inessential to ostensive naming: here are five.

1 References to Wittgenstein are to the 2009 Revised 4th edition of Philosophical Investigations by P.M.S. Hacker and J. Schulte (Wiley-Blackwell). 
First: there is nothing special about the religious or other official surroundings of baptism and christening. A civil official could equally well name a baby, say, and a private individual can do this, e.g. with her pets.

Second: there is nothing special about the objects of the ceremony: it is possible to name insentient things much as we name persons. Somebody in an appropriate position could certainly name a river or a continent, or a planet or a star. In these cases, the 'appropriate position' may be that of being the first in his linguistic community to have discovered the item that is being named.

Third: we can name kinds of object as well as spatio-temporally located individuals. Somebody in an appropriate position regarding a disease or a species of plant or an element can dub its kind by pointing to an instance of it and saying 'I name this virus/species/element so-and-so' (Kripke 1980: 135-6). Here the appropriate position may be that of having been the first person in one's linguistic community to have identified instances of the kind as such.

Fourth: there is no reason why ostensive naming should merely be a device for fixing the reference of a term. It would also be possible ostensively to specify the sense expressed by some sentence. 'When the weather is like this I'll say that it is X-ing' ostensively fixes the reference of ' $\mathrm{X}$ ', but it may also ostensively fix the sense of 'It's X-ing. Similarly, Wittgenstein's diarist introduces ' $\mathrm{S}$ ' as a name for some type of sensational state; but in addition, he introduces ' $\mathrm{S}$ ' as written in the diary as a sentence reporting the occurrence of some sensational event of that type.

Fifth: no one behavioural prop belongs necessarily to ostensive naming. You can name an object without pointing to it if you and your audience are already attending to it. You can even name an object without saying its name out loud-but only to yourself; at least you can if the name is meant only for personal use.

Appreciation that all these features of the paradigm case are inessential to ostensive naming can create what Wittgenstein regarded as the danger of philosophical 'sublimation' (PI 38), of the solid facts about language-use into gaseous speculations about a mental realm lying behind them. For instance, once we see that no single kind of behaviour distinguishes the mere utterance of a sign in the presence of an object from the act of naming the object with the sign, the danger is that we will 'do here what we do in a host of similar cases: because we cannot specify any one bodily action which we call [naming something], we say that a mental, spiritual activity corresponds to these words' (PI 36).

It is then a short step to thinking that the act that turns the dead sign into a living symbol can-just because it is a mental act-correlate a sign 
with any object of awareness, external or internal. It can seem that a mental act of correlation between a sign and a private sensation can by itself make the sign into a propositional symbol reporting the occurrence of some instance of that sensation. This commits you to the view that such a oneoff act of naming can cast a kind of shadow over your future utterances or inscriptions of ' $S$ '. It sorts them into true and false: subsequent utterances of ' $S$ ' are true if and only if accompanied by a sensation of the same type as that originally ostended; and subsequent inscriptions of ' $S$ ' in a diary or calendar are true if and only if entered under a date on which a sensation of that type did in fact occur.

Certainly some ostensive definitions of external objects or types of object can cast just such a shadow. But what Wittgenstein claims at PI 258 is that our semantic fiat over public objects, events or states of affairs cannot be directed inwards: in particular, that it cannot correlate a name with, or a sentence with the instantiation of, a private sensational type. These are, he says elsewhere, types that have no known public characteristics (PI 243). ${ }^{2}$

For instance, suppose that instead of typically being caused by the observable circumstance of sitting in one position for a long time, occurrences of what we call 'pins and needles' came and went apparently at random. Then it seems that any of us could via a mental act of correlation introduce the expression ' $S$ ' to record occurrences of that feeling. ' $S$ ' then belongs to a private language and its means of introduction is a private ostensive definition. This is an instance of Wittgenstein's target, the thesis that I shall label $(\mathrm{T})$ :

(T) It is possible to introduce ' $\mathrm{S}$ ' by means of a private ostensive definition.

The conclusion of what I'm calling the Private Language Argument is that (T) is false. Before saying why I think it's false, let me place two restrictions on the sort of argument against (T) that I'll be discussing.

\subsection{Arguments against (T)}

The first point is that I'll only be concerned with a priori or at least relatively a priori arguments against (T). By this I mean to rule out arguments that rely on empirical discoveries in psychology or neuroscience bearing upon normal human learning of a word via ostensive definition. The arguments that interest me will rely only upon such 'general facts of nature' as are readily available to casual observation.

2 So we may allow that like all other sensational types, what ' $S$ ' tries to report has 'external' correlates in the sense of neurological causes and physiological effects. We are only supposing that nobody knows what they are. 
The point of thus restricting my field of vision is (a) that it is necessary for reaching any definite conclusions in the space of a paper; (b) although specific reasons to deny (T) certainly have philosophical interest, it would be more interesting if the trouble with (T) lay in general and obvious facts about human beings, because the latter sort of trouble would generalize more widely than the former.

Second: I aim only to consider arguments of which the denial of (T) is the maximal product, i.e. not ones that happen to refute $(\mathrm{T})$ on the way to some stronger result. In particular, the arguments must show that the important line to draw amongst putative ostensive definitions is between those that are private and those that are not, rather than between those that fail, and those that meet, some more stringent condition than non-privacy that rules out other things besides.

To get an idea of the content of this restriction, note that it rules out consideration of what one might call Quine's private language argument. Quine wrote:

Entification begins at arm's length; the points of condensation in the primordial conceptual scheme are things glimpsed, not glimpses. In this there is little cause for wonder. Each of us learns his language from other people, through the observable mouthing of words under conspicuously intersubjective circumstances. Linguistically, and hence conceptually, the things in sharpest focus are the things that are public enough to be talked of publicly, common and conspicuous enough to be talked of often, and near enough to sense to be quickly identified and learned by name; it is to these that words apply first and foremost. (Quine 1960: 1)

Quine's premise, that we all learn language from others, is grounds to reject (T). Any ostensive definition that was private in the sense of $(\mathrm{T})$ would not define any term that another could convey to you: if ' $S$ ' describes the occurrence of an event for which no publicly available criteria are known then nobody else could tell you when you are right or wrong to say or write 'S'.

But that premise is also grounds for rejecting more than just $(\mathrm{T})$. If it establishes the impossibility of private ostensive definition then it also establishes the impossibility of solitary ostensive definition: i.e., an ostensive definition of a term or sentence denoting or describing a possibly public object, event, or type of either that the learner happens to frame and use without telling anyone else (as would happen, for instance, in the case of a congenital Robinson Crusoe). If we all learn language from others, then solitary ostensive definition is as impossible as private ostensive definition. 
So if Quine's premise is correct then no special difficulty arises for private ostensive definition. ${ }^{3}$

\section{The McGinn/Stroud interpretation}

Of the main interpretations of Wittgenstein's argument, I have space only to consider the most plausible; probably it is also the most faithful to Wittgenstein. This is due in essentials to McGinn and Stroud. ${ }^{4}$

The interpretation focuses on the relation between two things: on the one hand, the introspective episode that is meant to establish the meaning of ' $\mathrm{S}$ '; on the other hand, the subject's subsequent use of 'S'. The basic idea is that the former cannot determine the correctness or otherwise of the latter: no act of introspective 'ostension' can settle how ' $\mathrm{S}$ ' is supposed to be being used in the future.

When I 'speak or write the sign down, and at the same time concentrate my attention on the sensation', I do not thereby determine a linguistic technique for using... ' $\mathrm{S}$ '. There is nothing that can count as a correct use of ' $S$ ' in the future because there is no linguistic technique of using 'S' fixed by my act of looking inwards and concentrating on what I then feel... On this interpretation, there is quite clearly nothing in PI 258 that implies that language cannot connect with the inner; the whole force of the remark is that it cannot connect with it on the basis of acts of introspection. (1997: 131)

But why does a private ostensive episode fall short of 'determining a linguistic technique'? The clue is in PI 257:

When one says "He gave a name to his sensation", one forgets that much must be prepared in the language for mere naming to make sense. And

3 Although I am aiming at satisfying this restriction, I may actually fall short of this aim: for the argument that I eventually endorse may end up establishing a far stronger result than the denial of (T). See fn. 9 below.

4 McGinn 1997; see also Stroud 2001. Four other readings are: (i) The verificationist reading, according to which the disabling defect of a private ostensive definition is that it inevitably fails to specify a verification procedure for 'S' (Malcolm 1966: 60-70); (ii) A refinement of this, where what are unverifiable are claims about what I meant all along by 'S' (Kenny 1976: 192-5, Pears 2007: 44; Mulhall 2008: 96-7); (iii) The logical reading, according to which the trouble is that since the private linguist cannot be said to misidentify candidates for being called ' $S$ ', neither can he be said to identify them (Schroeder 2006: 211-4; Hacker 1990: 118-20, 130-132); (iv) Kripke's reading, according to which the trouble with a private ostensive definition is that nobody other than its user can judge whether his subsequent uses of ' $\mathrm{S}$ ' are in accord with the ostensive definition (1982: 109-13). I believe that Stroud (2001) has given good reasons to reject both (i) and (ii); and the defenders of (iii) have never given an argument from the possibility of identification to the possibility of misidentification. Kripke's argument, like Quine's, is beyond the scope of this paper, and for the same reason. 
when we speak of someone's giving a name to a pain, the grammar of the word "pain" is what has been prepared here; it indicates the post where the new word is stationed.

This passage-especially in its concluding metaphor-alludes to the discussion of ostensive definition that had appeared very much earlier in Philosophical Investigations, and specifically to the remark that 'the word "number" [in the ostensive definition "This number is called "two"'] shows what place in language, in grammar, we assign to the word' (PI 29).

In those earlier sections, Wittgenstein had said that any ostensive definition could be understood in any of indefinitely many ways. "That is called 'two', said whilst pointing at a group of nuts, might be taken as an ostensive definition of the number two, of a kind of nut, of a colour or even of a point of the compass (PI 28). In this case, is possible to avert that sort of misunderstanding by specifying that it is the number that one is calling 'two'.

Now in the case of private ostensive definition the same misunderstanding threatens to arise. What is there to assure his later self that the would-be diarist of PI 258 is introducing ' $\mathrm{S}$ ' as the name of one type of sensational episode, rather than as the name of some other type of episode to which the present experience also belongs? As Stroud points out (2001: 154), any future episode will resemble this one in some respect. For instance, suppose that the private linguist experiences a chromatic sensation that he has never had before (e.g. the 'missing shade of blue') and, whilst concentrating on that experience, utters the sign 'S'. Then what is there in that attempted definition to tell his future self that ' $S$ ' is the name of the colour that he then experienced rather than (say) of the brightness or of the shape that he then experienced?

Well, can't he settle this in the same way as we settled the difficulty with 'two', that is, by stipulating on the first occasion that ' $\mathrm{S}$ ' is to name this colour? The trouble is that 'colour' is a word of our public language, and similarity of colour is settled by external criteria that are available to everyone-and so in that case ' $\mathrm{S}$ ' does not after all belong to a private language. Somebody else might understand it as well as the subject.

More generally, any attempt to specify the relevant respect of similarity must be framed in either a private or a public language. If it is framed in a public language, then the ostensive definition of ' $S$ ' is no longer 'private'. But if it is framed in a private language then we are simply presupposing the connection between language and private episodes that the private ostensive definition was meant to underwrite (cf. PI 32). Either way, no private ostensive definition can by itself tie linguistic expressions to private sensational episodes. That is the conclusion of the Stroud-McGinn interpretation.

The trouble with it is that it isn't clear why the private ostensive definition needs to make any explicit stipulation about the relevant respect of 
similarity; all that is needed is that the baptism does in fact bring it about that the speaker respects it. Wittgenstein himself had already made the analogous point for public ostensive definitions. For instance, consider the specification that when I say "That is called "two" I mean that that number is called 'two'. That specification might avert the misunderstanding that 'two' is the name of a number and not e.g. of a colour. But the ostensive definition might well have been successful even without it. There is no inconsistency in supposing that my audience does in fact go on to use the expression in the way that I intended.

Whether the word "number" is necessary in an ostensive definition of "two" depends on whether without this word the other person takes the definition otherwise than I wish... And how he 'takes' the explanation shows itself in how he uses the word explained. (PI 29)

Applying this point to the 'private' case: suppose that the private ostensive definition in fact has the effect that the subject goes on to use ' $S$ ' for episodes that resemble the initial episode in some non-publicly-assessable respect R1 rather than in other such respects R2, R3 etc. And suppose that was indeed the respect of similarity that he initially intended. There is no inconsistency in these suppositions. ${ }^{5}$ And if they hold, the private ostensive definition is successful without having explicitly fixed that aspect of the subsequent correct use of 'S'.

Wittgenstein wrote:

'I commit it to memory' can only mean: this process brings it about that I remember the connection correctly in the future. (PI 258: my emphasis)

Whatever suffices for the right-hand side of this semantic equation suffices also for its left-hand side. But since as Wittgenstein himself has argued, a bare ostensive definition always could fulfil the condition on the right without explicitly specifying 'the post at which we station the word', it is surely possible for such an ostensive definition to commit the meaning of ' $\mathrm{S}$ '-that is, the conditions of its correct use-to my memory.

McGinn or Stroud might object at this point that we-that is, people other than the private diarist himself-have no reason to think that ' $S$ ' is being used as a term for a type of private sensation. After all, others' sensations are as Wittgenstein says (PI 256) 'tied up with their natural expressions'; and this ' $\mathrm{S}$ ' is by definition not tied up with any natural expression. So as far

5 But how are we to cash out this claim about the subject's intention at the time? We might do so in terms of a counterfactual conditional: were the diarist then-at the time of the baptism - to have had experiences that resembled the initial one in respects R1, R2 etc. it would be exactly those that resembled the initial sample in respect R1 that he would agree to call 'S'-type experiences. Cf. PI 187. 
as we can tell the private diarist is writing down 'S' entirely haphazardly. As far as we can tell, the private diarist is not using the ' $\mathrm{S}$ ' to denote or to report any type of episode at all, sensational or otherwise (McGinn 1997: 132; Stroud 2001: 155).

The point is correct but serves only to emphasize the privacy of the speaker's language - the fact that nobody else can understand it, or perhaps even recognize it as a language at all-and not to reveal any incoherence in it. From the premise that nobody else knows the meanings of the speaker's 'S', or even whether it has any meaning, it simply does not follow that ' $S$ ' is in fact a meaningless squiggle. At least it does not follow without some verificationist premise to the effect that nobody ever means anything by a word unless other people can tell what he means by it. But if we had that premise to hand then we could have directly reached the conclusion that ' $S$ ' is meaningless however it had been introduced: there would have been no need for a relatively elaborate argument that private ostensive definition suffers any special defect.

McGinn has also said something that suggests a different objection. It is essential to private ostensive definition that the diarist 'directs his attention' to the initial instance of the sensational type that he is dubbing. But how does he achieve this 'directing of his attention'? As Wittgenstein observes, he cannot point at it in the ordinary sense, i.e. with his finger: one could only point at something in that way if anyone else could too. Instead one must do a 'mental' pointing, of which McGinn says that it is done not with the finger but 'with the imagination'. She continues:

In order to get us to see that 'pointing to a sample in (or with) the imagination' is not an instance of pointing to a sample, Wittgenstein also offers a number of other comparisons. We would not want to say that looking up a table in the imagination is looking up a table [PI 265], nor that the imagined result of an experiment is the result of an experiment [PI 265]. And nor would we want to say that looking up a clock in the imagination is a way of determining the time [PI 266]... In the same way, pointing to an object with (in) the imagination is not an instance of pointing to an object... Thus the very idea that pointing to a sample with (or in) the imagination is an instance of pointing to a sample is completely idle or empty. (1997: 137)

This new argument is that, far from assigning to ' $\mathrm{S}$ ' the type of a privately exhibited item, the private diarist has not so much as exhibited anything to himself in the first place. Even if I was right that private ostension needn't explicitly specify the respect of similarity that is supposed to govern 'S', still it must at least specify the initial sample. But because this 'specification' takes place in the medium of the imagination, it doesn't even manage to do that. An 'ostension in the imagination' is an imaginary ostension, that is, not an ostension at all. 
But what settles whether the ostension is successful is whether it succeeds in drawing the audience's attention to the object or type that the subject intends. When the audience includes persons other than the ostender it is natural to expect that this demands a visible or otherwise sensible gesture on the part of the ostender, because that is the only sort of act that the audience can perceive. But when ostender and audience are the same person, that demand lapses. It seems on the face of it that I can ostend a public object to myself simply by focusing attention upon it. Why not also a private one?

McGinn will object that the ostender has not really picked out anything but has only imagined doing so. But the argument form, from the premise that one Fs in the medium of the imagination to the conclusion that one is not really F-ing at all, is invalid. It is true that looking at a clock in the imagination is not the same thing as looking at a clock, and that imagining an experiment falls short of doing it. But it is not true that calculating (counting, adding, etc.) in the imagination falls short of real calculation. 'It is real-calculation-in-the-head' (PI 364); to carry out a calculation in one's imagination is to carry out a calculation. We needn't dispute whether the private diarist's ostension takes place 'in the medium of the imagination'; but the issue that remains-which McGinn says nothing to resolve-is whether it therefore belongs with experiments, in the category of things that cannot be done just 'in the imagination', or whether it belongs with calculation in the category of things that can.

Ultimately, whether a mental or bodily act counts as an ostension of something will depend on whether it has the intended effect on the learner and thus, in Wittgenstein's words, on 'the use that he makes of the word defined.' If the act of private ostensive definition does indeed have the effect that the diarist goes on to use ' $S$ ' in the manner that he initially intended, there is nothing to stop us from saying that that definition involved an act of pointing that is as real as any bodily gesture. So unless we have independent reason to deny that private ostensive definition has this effect, there is no reason that I can see to doubt that ostension really took place. ${ }^{6}$

\section{Triangulation}

Is there any other reason to think that private ostensive definition is futile? McGinn and Stroud were right to focus on the alleged connection between the initial act of private ostension and the subsequent use of ' $S$ '; right also to

6 I should emphasize: I am not claiming that 'pointing in the imagination' is sufficient for securing a meaning for ' $\mathrm{S}$ ', but only that it is for all that McGinn says. My own interpretation of the argument is consistent with the claim that the diarist successfully points ('in his imagination') at the initial sample whilst saying ' $S$ ' to himself. The point will rather be that even if this happens, it is still not sufficient for ' $S$ ' to be a report of the instantiation of a type to which that sample belongs, but for reasons quite different from those that we have seen so far. 
claim that the former is impotent in principle to underwrite the latter. But the claim needs a different argument.

\subsection{The diarist's private practice}

Let us start by looking at what happens from God's point of view, that is, under the idealizing assumption that we can see into the diarist's mind. What we are looking at, then, is a pattern of linguistic responses (either writing ' $S$ ' or not writing ' $S$ ') to various inner events that we can also 'see.' Let us allow that some sensational event really does occur on the occasion that ' $S$ ' is introduced to the language (call this the initial sample) and that traces of it in the diarist's mind commemorate this.

What we see is this. The diarist suffers an episode of a type of sensational state. He concentrates on that sensational state whilst saying 'S'. The effect of this is to set up a stimulus-response association: if on any later day he has a sensation that matches in some relevant respect, or is within some maybe vaguely delimited range of, his memory of the initial sample, he writes ' $S$ ' in his calendar or diary under that day. Match with his memory of the initial sample is the only criterion governing the diarist's classification of subsequent sensational items that do, and those that do not, deserve the label ' $S$ '. This classificatory practice (as it seems to be) is the whole of the private diarist's use of 'S'.

Now it looks as though the behavioural/sensational pattern that I just described is properly described as a case of ostension in which ' $\mathrm{S}$ ' has been introduced as a term denoting some sensational type to which the initial sample belongs, and its entry on a page of the diary as a sentence stating the occurrence of a token of that type on the day for which the entry appears. But I claim that that is not the correct description of the situation: there is a crucial feature of the situation that stops those from being the right things to say about this case. It will be clearer why this feature is crucial once we have appreciated two other features of the situation that are not.

One striking feature of the situation is that it involves only a very primitive pattern of behaviour, i.e. just classificatory behaviour. The private linguist doesn't talk about $S$; he doesn't embed ' $S$ ' in larger sentential contexts; he doesn't speculate as to its causes or effects; in fact he does nothing with ' $\mathrm{S}$ ' beyond the primitive diary-keeping that PI 258 describes. This is clearly one respect in which his use of ' $\mathrm{S}$ ' falls short of the everyday use of terms that many of us learnt by ostensive definition, e.g. names of people.

But it is not a crucial respect, I think. To see this, consider that it is easy enough to imagine a public practice that is just as primitive and of which we should not hesitate to say that its terms successfully refer. Thus consider a variant on Wittgenstein's first language game involving two builders (PI 2). In this variant, $\mathrm{A}$ teaches $\mathrm{B}$ names for types of objects by pointing to their 
instances and uttering the word, e.g. 'block', 'pillar', 'slab', 'beam'. Subsequently A shows items of one or another type-a block, a pillar, a slab or a beam-to B. And because of the initial ostension, B typically calls out the right name: 'block' when shown a block, 'pillar' when shown a pillar etc. We could even imagine, as does Wittgenstein (at PI 6) of an equally simple pattern, that this practice is the entirety of the language of $\mathrm{A}$ and $\mathrm{B}$. So here we have a pattern of linguistic behaviour that is just as barely classificatory as that of the private diarist. And yet it is clear enough that $\mathrm{A}$ and $\mathrm{B}$ are playing a language game in which ostensive definition has set up 'block', 'pillar' to be terms respectively denoting blocks and pillars. The purely classificatory nature of the private diarist's practice cannot be the source of the trouble.

A second striking feature of the private diarist's situation is that his initial sample of $S$ no longer exists. It was there when he introduced ' $S$ ' into his language but now it is gone. This is certainly not the situation in every uncontroversial case of ostensive definition. Typically if I ostensively define a type-expression, say, 'sepia', as the colour of that sample over there, then it is at least in principle possible to settle the correctness of subsequent disputes as to whether some object, say a coloured surface, falls under the extension of that term by going back to the initial sample and directly comparing it with the object whose status as in instance of the relevant type is in dispute.

But this does not always happen with genuine ostensive definitions; and as far as I can see it need not ever happen. It is entirely possible that the initial sample should cease to exist and yet continue to underwrite the reference of a term in its subsequent and post-mortem uses, so to speak at a distance. This will happen just so long as the initial sample leaves traces that commemorate its relevant features and through which it enters by proxy into classificatory exercises involving the term. E.g. suppose that (colour!) photographs of the initial sample of sepia are still in existence, that everybody has such a photograph in her possession, and that each of us classifies coloured surfaces as 'sepia' or not based on whether the surface matches-or resembles, possibly to a vaguely specified degree-her photograph. If the photographs all agree, there seems nothing wrong with saying that under this regime of use the term 'sepia' refers to the chromatic type to which it had been ostensively assigned, back when the initial sample still existed.

But the initial sample is commemorated in the private case too, by the diarist's memories of it. Whatever exactly memory is, it is plausible that like photography, it at least involves some sort of causal process connecting the type remembered to its present memory traces. ${ }^{7}$ The private diarist's memory trace of the initial sample directs his use of ' $S$ ' in the way that everybody else's photographic trace of its initial sample directs her use of 'sepia. The passing away of the initial sample in the former case is no more problematic in the former case than in the latter.

$7 \quad$ Martin and Deutscher 1966. 


\subsection{Indeterminacy of the private practice}

But now, what about the fact that his memory is the only medium in which he can compare candidate instances of ' $S$ ' with the initial sample? This is the fact to which Wittgenstein alludes at PI 265 when he points out that there is no (memory-independent) way for the private diarist to check his memory of the initial sample. And in fact it is this feature of the case that the private diarist has only his memories to go on, that is the fundamental difficulty with private ostensive definition. The argument for this is an underdetermination argument.

Given the description of the private diarist's practice, there are (at least) two possible interpretations that we (or God) might give to 'S.' One hypothesis is that ' $S$ ' refers to the original felt quality of the initial sample. The other hypothesis is that at any later time $t$, ' $\mathrm{S}$ ' refers to his memory at time $t$ of the initial sample. Now if the memory of the initial sample is accurate, the two hypotheses imply the same about the truth-value of any entry of ' $\mathrm{S}$ ' in the diary. But suppose that the memory-image changes over time. Because his memory image at any time constitutes his only clue as to the original quality, the diarist will not notice this difference. In that case the two hypotheses are inequivalent: given his actual classificatory behaviour, the first hypothesis implies that he falsely writes down an entry 'S' for days in which his sensation matches his memory image of the initial sample, whereas the second hypothesis implies that he truly writes 'S' on those days.

But both hypotheses are equally compatible with his actual behaviour despite entailing different extensions for ' $S$ '. Hence the reference of ' $S$ ' as a term, and the truth-value of ' $S$ ' as a sentence, are both underdetermined by the private diarist's classificatory behaviour: as long as ' $S$ ' remains part of a private language in which the only traces of the initial sample are the private diarist's memory traces of $S$, nothing that we can see, or that God can see, justifies preferring one hypothesis about its reference over the other. And that means that there is no room in his practice for the idea that ' $S$ ' refers at all.

\subsection{Determinacy and Indeterminacy in the public sector}

The following analogy shows that a pattern of classificatory behaviour as impoverished as the private diarist's faces the same difficulty whether 'external' or 'internal': it also indicates why 'external' ostensive definitions do not usually face this problem.

On 1 January 2018 Smith visits some shop selling interior furnishings. Smith sees a roll of wallpaper in a colour that he thinks would suit his livingroom. He takes away a sample (a patch of wallpaper of that colour), dubs its colour ' $\mathrm{S}$ ', and on returning home finds that indeed it goes very well. Returning to the shop that afternoon, he finds that the shop has been shut down and its inventory sold off: he cannot buy the wallpaper that he wants. 
Moreover Smith is hopeless at remembering colours, and he certainly has no recollection of the exact shade. Still, he has a sample of the colour that he wants, and so he takes it with him to various retailers looking for rolls that match. He becomes slightly obsessional about this project and it goes on for years. Because of the importance of his quest he keeps a note of its progress, making an entry of ' $S$ ' in his diary under days on which he finds paper that matches his sample.

On the same morning, Jones also visits the same shop and buys the same wallpaper, in a quantity that she thinks is enough to paper her livingroom; she too dubs its colour 'S'. Jones doesn't care greatly about the specific colour: what matters to her is only that her living-room has a uniform décor. That afternoon Jones discovers there isn't quite enough to paper the whole living room and so returns to the original shop, only to find that it has shut down and its stock has been sold off. So Jones tears off a sample from her half-papered wall and sets off in search of an affordable roll that matches it. Like Smith she keeps a record of her search (which also goes on for years), writing ' $\mathrm{S}$ ' in her diary under days on which she finds a roll that matches her sample.

Now if we look only at that part of Smith's and Jones's behaviour that corresponds to the whole of the private diarist's behavior-that is, the initial dubbing and consequent classificatory practice involving ' $S$ ' - we see that they match. Both agents have uttered ' $S$ ' whilst focusing on a wallpaper sample of a particular colour and gone on to enter ' $S$ ' for just those days on which he or she comes across a roll that matches the sample. And yet the term ' $S$ ' refers to different things in their respective idiolects. For Smith, ' $\mathrm{S}$ ' refers at any time $t$ to whatever matches the original colour of the paper in the shop i.e. its colour on January 1, 2018; whereas for Jones, 'S' refers at $t$ to whatever matches her portable sample at $t$.

To see how this difference in references involves a difference in the behavioural dispositions of these parties, we need only suppose that Smith and Jones have other sources of information about the colour of the wallpaper in the shop on 1 January 2018. Imagine that after three years some former employee of the original retailer reveals that the batch of wallpaper that was on sale on 1 January 2018 had been produced using a dye that gets lighter over time, so that after three years its colour has quite changed. Smith and Jones would react quite differently to this news. Smith would no longer write 'S' when he finds rolls of wallpaper that match his sample. Instead he would do so only when he finds rolls that are somewhat darker than his sample, because he wants the original colour. But Jones will continue to write ' $\mathrm{S}$ ' whenever she sees rolls that match her sample, because she wants a roll that matches the present décor of her living-room, and both the paper in her living-room and the paper that constitutes her sample will have lightened at the same rate. 
We may sum up the difference between these reactions by saying that Smith is using his sample transparently, i.e. as a medium for comparing wallpapers with the colour of something in the past. Whereas Jones is using her sample opaquely, i.e. as a present standard of comparison against which she measures rolls of wallpaper that she now encounters.

This difference in their dispositions to react to the news from the exemployee is what makes it correct to distinguish the temporal locations of Smith's and Jones's standards of comparison. We can characterize the difference more generally as follows: if on a particular day Smith and Jones both find a roll of wallpaper matching the sample, Smith will, but Jones will not, be prepared to revise his decision to write ' $S$ ' in the face of conflicting evidence about whether the original colour matches the roll. In the present example that conflicting evidence was the testimony of the ex-employee, but it could have been anything else that played the same role given Smith's and Jones's beliefs. For instance, it might have been a photograph of the original wallpaper taken on 1 January 2018 (assuming that the photograph is known by Smith and Jones not to fade, or at least that it fades at a rate known to both). All that is necessary is that there be a possibility of conflict between the alternative source of evidence and the evidence that a match with the sample supplies.

But without any such source of conflicting evidence and so without any dispositional difference between Smith and Jones, there is simply nothing in their classificatory behaviour to settle-for us or even for God-whether either of them is making a comparison with the initial sample or with its contemporary descendant. And that just means that here we can't talk about any such 'comparison'. But since what the term ' $\mathrm{S}$ ' denotes is the colour of the object of the comparison, we can't talk about the reference of the term ' $\mathrm{S}$ ' in the language of either, nor of the truth-value of inscriptions of ' $S$ ' in either person's diary.

The same indeterminacy affects the private diarist. When he writes ' $\mathrm{S}$ ' is he reporting the match between his present sensation and the initial sample, or between his present sensation and his present memory of the initial sample? ${ }^{8}$ Either hypothesis is compatible with the totality of his behavioural dispositions: which is just to say that both hypotheses cut finer than the facts.

8 I am here for vividness engaging in the fantasy of PI 265 that the exercise of memory consists in the comparison of objects of present awareness with memory images. Of course nothing like that usually happens, but the fiction is useful for making the argument clearer. The exercise of memory more often consists in the formation of a judgment without the intervention of any 'memory image' at all. But this makes no material difference to any of the points that I want to make (or to many of the points that Wittgenstein wants to make). I could instead have argued, more generally but along the same lines, that there is an indeterminacy, in the private linguist's case, between (i) the hypothesis that at any $t$ ' $S$ ' denotes the felt quality of the initial sample; and (ii) the hypothesis that at any $t$ it denotes the felt quality that at $t$ he remembers it as having had. 
What would show that one or the other hypothesis was true would be a memory-independent source of information about the original sample, i.e. of a sort analogous to that which I introduced at the end of the Smith/ Jones example. For instance, suppose that his exposure to the initial sample took place when one of his fingers was being pinched; suppose further that he knows this. Now it may happen that on a subsequent occasion he finds himself suffering a sensation that matches his memory image of the initial sample; but he resists writing ' $\mathrm{S}$ ' in his diary because he sees that none of his fingers are being pinched, and he regards that as being evidentially relevant to the question whether he is now having $S$. That would be inexplicable if 'S' just referred at $t$ to whatever at $t$ he remembered the initial sample to be; on the contrary hypothesis, that ' $S$ ' referred to the felt quality of the initial sample, it is just what you would expect.

But in the absence of any such sensitivity to any alternative-that is, any memory-independent-channel of evidence, there is no getting away from the indeterminacy over the reference of 'S'. And it seems to me that the privacy of the sensation is just what excludes such alternative channels. That sensation type is private in the sense that it has no known causes and no known effects other than via the memory of the diarist; hence as far as the diarist is concerned there cannot be any alternative channels of evidence. So it seems that indeterminacy of reference is an inevitable feature of the privacy of its user's situation. ${ }^{9}$

9 One objection to this argument is that it seems to be arbitrarily restrictive. After all, if the possibility of reinterpretation of a subject's linguistic use is enough to rule out any particular interpretation of it, then surely the problem extends beyond private language. For instance, Quine has argued for a quite general method of reinterpretation, of public as well as private language, in terms of proxy functions (1981: 19-21). I can only make a few sketchy remarks in response to this objection.

My inclination is to bite the bullet, and to concede that the Private Language Argument is really a special application, to an area of thought where it seems most implausible, of an argument that has more general application. (For a similar argument concerning PI 293, see my 2010: 126-8.) All that Wittgenstein's argument does is to identify a special kind of indeterminacy (i.e. between reference to the present and reference to the past) that afflicts the would-be user of ' $\mathrm{S}$.' On this view, I must give up on the aim of identifying an argument of which the denial of $(\mathrm{T})$ is the 'maximal' product (see section 1.2).

But an alternative response would be to argue-though I have not done so here-that in the private case the indeterminacy is somehow deeper: not only is it not settled what the private diarist's term ' $S$ ' denotes; it is unsettled whether it denotes anything at all. The reason is that we can understand the diarist's ' $S$ ' as not referring to anything at all: we (or God) could equally account for his behaviour by interpreting the inscription ' $S$ ' adverbially, so that it says so to speak 'I am remembering S-ly'. There need be no mention of any objects of reference in this account because nothing in his behaviour demands such a reference. (Note by contrast that in Quine's 'proxy function' argument for the inscrutability of reference, all reinterpretations of a term assign something to that term; so it is in a sense still determinate that 'reference is going on.) I have written elsewhere (2007: section 2.3 .2 ; 2017) about what it would take for a systematic description of a pattern of linguist behaviour to demand reference to objects. That a Wittgensteinian private language falls short of meeting those conditions seems to me to be an interesting question that I hope to pursue further elsewhere. 


\section{Conclusion}

Wittgenstein was therefore right to say, as he does at PI 258, that there is something wrong with the kind of report of which I can say that 'whatever seems right to me is right'. On the 'logical' interpretation of this argument (see (iii), n.4), this implies that the diarist is not after all identifying any inner object, because the possibility of identification implies the possibility of misidentification. But it is hard to see why the possibility of identification implies the possibility of misidentification.

Wittgenstein was also right to insist that the uncheckability of the diarist's memory of the baptismal sample is what causes the problem for the private diarist, as he does at PI 265. On the verificationist interpretation of the argument (see (i), n.4), the point of the appeal to uncheckability was supposed to be that an uncheckable claim is unverifiable and therefore meaningless. But as Ayer (1954) pointed out, if my having to rely on memory to check a claim makes it meaningless then the impossibility of private language is the least of our worries: most of what we say about the external world would also be meaningless.

On the present interpretation, both remarks find a different place. The significance of 'whatever seems right to me is right' is that this is an alternative hypothesis about the reference of 'S': that 'S' denotes not the felt quality of the initial sample but rather whatever matches the diarist's present recollection of it. On this hypothesis, whatever seems right to him is right. There is nothing wrong with that being true about ' $S$ ': the trouble is that it is an available hypothesis about reference that is alternative to the hypothesis that 'S' denotes what the ostensive definition was supposed to make it denote. And the significance of uncheckability is that if the diarist's recollection of the initial sample is uncheckable, then nothing in the private diarist's behavioror anywhere else-rules out that alternative hypothesis. If God had looked into his mind he could not have seen there what ' $S$ ' means. And that just means that ' $\mathrm{S}$ ' doesn't have a meaning. ${ }^{10}$

\section{References}

Ahmed, A. 2007. W.V. Quine. In Misak, C. (ed.), Oxford Handbook of American Philosophy. Oxford: OUP: 290-338.

Ahmed, A. 2010. Wittgenstein's 'Philosophical Investigations': A Reader's Guide. London: Continuum.

Ahmed, A. 2017. Signaling systems and the Transcendental Deduction. In Goldschmidt, T. and K.L. Pearce (ed.), Idealism: New Essays in Metaphysics. Oxford: OUP: 104-123.

10 I wish to thank Slobodan Perović and an anonymous reviewer for BPA for their most helpful written comments. I wish also to thank prof. Nick Treanor for very helpful comments on an earlier version of this paper. 
Ayer, A.J. 1954. Can there be a private language? Proceedings of the Aristotelian Society Supplementary Volume 28: 63-76.

Fogelin, R.M. 1987. Wittgenstein. Second Edition. London: Routledge.

Glock, H. 1986. A Wittgenstein Dictionary. Oxford: Blackwell.

Kenny, A. 1976. Wittgenstein. Harmondsworth: Penguin.

Kripke, S. 1980. Naming and Necessity. Oxford: Blackwell.

Kripke, S. 1982. Wittgenstein on Rules and Private Language. Oxford: Blackwell.

McGinn, M. 1997. Wittgenstein's 'Philosophical Investigations'. London: Routledge.

Martin, C.B. and M. Deutscher. 1966. Remembering. Philosophical Review 75: 161-96.

Mulhall, S. 2007. Wittgenstein's Private Language. Oxford: OUP.

Pears, D. 2007. Paradox and Platitude in Wittgenstein's Philosophy. Oxford: OUP.

Quine, W.V. 1960. Word and Object. Cambridge, Mass.: MIT Press.

Quine, W.V. 1981. Things and their place in theories. In his Theories and Things. Cambridge, Mass.: Harvard UP: 1-23.

Schroeder, S. 2006. Wittgenstein. Oxford: Polity.

Stroud, B. 2001. Private objects, physical objects and ostension. In Charles, D. and W. Child (ed.), Wittgensteinian Themes: Essays in Honour of David Pears. Oxford: OUP: 143-162. 